Journal of Southeast Asian

\title{
[Special Issue on Hmong Newcomers to Saint Paul Public Schools] Supporting Hmong Newcomers Academic and Social Transition to Elementary School
}

\author{
Martha Bigelow \\ University of Minnesota, mbigelow@umn.edu \\ Letitia Basford \\ Hamline University \\ Esther Smidt \\ Minnesota State University, Mankato
}

Follow this and additional works at: https://docs.lib.purdue.edu/jsaaea

Part of the Asian American Studies Commons, and the Bilingual, Multilingual, and Multicultural Education Commons

\section{Recommended Citation}

Bigelow, Martha; Basford, Letitia; and Smidt, Esther (2008) "[Special Issue on Hmong Newcomers to Saint Paul Public Schools] Supporting Hmong Newcomers Academic and Social Transition to Elementary School," Journal of Southeast Asian American Education and Advancement: Vol. 3 : Iss. 1, Article 2. DOI: 10.7771/2153-8999.1098

Available at: https://docs.lib.purdue.edu/jsaaea/vol3/iss1/2

This document has been made available through Purdue e-Pubs, a service of the Purdue University Libraries. Please contact epubs@purdue.edu for additional information.

This is an Open Access journal. This means that it uses a funding model that does not charge readers or their institutions for access. Readers may freely read, download, copy, distribute, print, search, or link to the full texts of articles. This journal is covered under the CC BY-NC-ND license. 


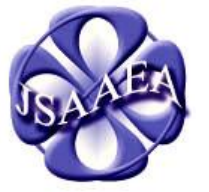

Volume 3 (2008)

\section{Journal of Southeast Asian American \\ Education \& Advancement}

WWW.JSAAEA.org
A peer-reviewed

scholarly journal

published by the

National Association

for the Education \&

Advancement of

Cambodian, Laotian, and Vietnamese Americans (NAFEA)

\title{
Special Issue on Hmong Newcomers to Saint Paul Public Schools \\ Supporting Hmong Newcomers' Academic and Social Transition to Elementary School
}

\author{
Martha Bigelow \\ University of Minnesota \\ Letitia Basford \\ Hamline University \\ Esther Smidt \\ Minnesota State University, Mankato
}

\begin{abstract}
When elementary aged Hmong children were resettled in St. Paul Public Schools after the closing of the Wat Tham Krabok refugee camp in Thailand, their families largely enrolled them in either a Transitional Language Center or a Language Academy program. This study reports on the perceptions teachers and educational assistants had about how well these programs met the needs of this unique population of newcomers. Findings show that the Transitional Language Centers were better able to ease the adjustment to school for the Hmong newcomers because of the safe, bilingual environment they created.
\end{abstract}

In anticipation of the arrival of approximately 1,000 Hmong newcomers from the Wat Tham Krabok (hereafter, "the Wat") refugee camp in Thailand, the Saint Paul Public School District (SPPS) joined together with a wide range of stakeholders to develop an education program that would specifically address the needs of their new students. ${ }^{1}$ The committee created what they believed would be "a Cadillac model": the best possible program for incorporating the language, academic, health, social, and emotional needs of the Hmong children and their parents, all under one roof within a traditional elementary school. ${ }^{2}$ What resulted from these conversations was the establishment of Transitional Language Centers (TLCs) at five elementary schools during the 2004-2005 academic year and two in the 2005-2006 academic year. The TLCs were intended to be temporary programs specifically tailored to the Hmong newcomers from the Thai refugee camp.

\footnotetext{
@)

SORERIGHISRESERVEDReaders are free to copy, display, and distribute this article, as long as the work is attributed to the author(s) and the Journal of Southeast Asian American Education \& Advancement, it is distributed for noncommercial purposes only, and no alteration or transformation is made in the work. More details of this Creative Commons license are available at http://creativecommons.org/licenses/by-nc-nd/3.0/. All other uses must be approved by the author(s) or JSAAEA.
} 
Bigelow, Basford and Smidt: Supporting Hmong Newcomers' Academic and Social Transition

The TLCs were completely new in the district. However, they did not replace the longstanding and highly regarded Language Academy (LA) programs that typically serve newcomers from a variety of linguistic and cultural backgrounds. Therefore, Hmong parents were given the choice to enroll their children in either program. ${ }^{3}$ This fact offered the unique opportunity to compare how a group of newcomers with similar backgrounds fared in two programs tailored for newcomers at the elementary grades. In particular, we were interested in discovering the features within the TLC and LA programs perceived by educators to be important in meeting the educational needs of the Hmong newcomers.

\section{Literature Review}

\section{Newcomers in U.S. Public Schools}

It is mandated that English Language Learners (ELLs) receive equitable public education (Lau $v$. Nichols, 1974) and have access to the same challenging academic content as their nativespeaking peers. It is hoped with this provision that ELLs would have the opportunity to soon be on par with their native-speaking peers. However, many ELLs have low educational attainment and high drop-out rates. The Hmong, in particular, have had many educational challenges in U.S. public schools. Data from the 2000 Census found that 59.7\% of Hmong Americans age 25 and older had not completed high school. In 2000, 27.2\% had a high school diploma, $11.7 \%$ held bachelor's degrees and 1.5\% held Master's degrees or higher (Hmong 2000 Census Publication: Data and Analysis, n.d., p. 57). Hmong students continue, after many years, to be placed and remain in low-level or remedial academic programs (Um, 2003).

Limited formal schooling and low print literacy ${ }^{4}$ presents one of the greatest challenges to schools today because these characteristics often accompany weak native language literacy and school readiness skills. Data from the 2000 Census indicate that almost half $(45.3 \%)$ of the Hmong American population have had no formal schooling compared to only $1.4 \%$ of all U.S. population (Hmong Cultural and Resource Center, 2004).

Background knowledge in academic content areas and native language literacy, as well as exposure to early schooling experiences are all highly valued resources that many children bring with them to the U.S. classroom. However, many newly-arrived Hmong children from refugee camps, such as the children central to this study, have not been exposed to these early literacy practices. Born and raised in refugee camps, books are scarce, formal preschools nonexistent, and parents - many of whom come from interrupted schooling backgrounds themselves - are unable to provide the early education preparation promoted by U.S. schools (Grigoleit, 2006). An assessment team from the Minnesota Department of Health that visited the Wat Tham Krubok refugee camp in 2004, immediately prior to the arrival of families to Minnesota, found that boys averaged 3.3 years of education with $20 \%$ having no formal schooling. Girls averaged 2 years of schooling and $37 \%$ had no formal schooling in the camp (Walker, 2004).

U.S. public schools are typically unequipped to teach newcomers with this degree of low literacy and limited formal schooling. This fact puts newcomers immediately at risk upon enrollment in school. There are other factors to take into consideration as well. Townsend and Fu (2001) warn that if teachers are not aware that some of their English language learners have limited print literacy skills in their native language, they might be apt to confuse low skills for low intelligence. In their study documenting the experience of a Hmong female elementary student in a mainstream classroom, the researchers found that teachers lowered their expectations 
of what she could achieve in comparison to her peers. In some cases, non-English speaking Hmong students have been erroneously diagnosed and referred to special education programs because of their lack of English language proficiency (Um, 2003).

The achievement data as well as the available educational research on Hmong immigrants should raise concerns. Nevertheless, the power of the dominant discourse or mainstream U.S. culture to minoritize and marginalize Hmong students plays an important role in the students' success. It is often the case that immigrant children simply posses knowledge that is not highly valued in typical school settings. Often their home or community-based literacies are not leveraged in the instruction they receive. In other words, while it is understandable that educators see newcomers as having many "challenges," or "gaps," it is important to refrain from falling into a deficit discourse. This impedes educators from seeing students' strengths and in many cases leads to low expectations for immigrant youth (Grant \& Wong, 2003). The challenge for schools is to design a program that addresses newcomers' needs and at the same time allows them to thrive in their new school.

\section{The Difficult Choice of Integration or Separation of Newcomers}

Educators know that newcomers have particular needs and that these needs vary according to factors such as the amount and quality of prior schooling and their level of native language literacy. Schools vary in how they choose to serve newcomers. Some schools completely ignore the specific needs of their newcomers and others design entire newcomer schools. While the perils of ignoring newcomers are clear, there is always the danger that the newcomer school is a means to segregate newcomers and "hide these students and their needs from public view" (Feinberg, 2000, p. 221).

\section{The Integrated Approach}

Many schools place their newcomers within existing school programs with the goal of providing students with access not only to the grade-level curriculum but also to peers with high(er) levels of English language proficiency. Yet "submersing" students into mainstream classrooms without any access to the child's first language or culture can result in negative consequences both academically and socially (Cummins, 1988). Without the proper learning environment, students will have significant delays in developing relationships with teachers and peers. Students might thus spend their first schooling experiences in the United States in isolation because of their inability to comprehend the instruction and connect with others. One of the key challenges is that teachers are frequently untrained in how best to meet the academic needs of newcomer youth and can feel overwhelmed:

Mainstream teachers get frustrated ... many complain, "This kid doesn't know how to read, has never been to school." "This child is in the fourth grade and doesn't know how to hold a pencil-I'm going to have to teach this all over again." It means a lot of extra work. Many teachers feel overwhelmed. The newcomer child is the straw that breaks the camel's back. In a regular classroom, we don't have the time to work with the newcomers because we have too many other kids to deal with. (Chang, 1990, p. 9)

While in an ideal world all teachers would know how to differentiate instruction and offer a 
culturally welcoming learning environment to newcomer students, we know that this is often not the case- even in our best schools.

Many schools have improved greatly on the submersion option by bringing in ESL teachers to co-teach with grade-level teachers or by assigning educational assistants to classrooms with newcomers. Other common options for newcomers at the elementary level include traditional English as a second language (ESL) programs that typically assume that students have native language print literacy skills. However, these programs have not been found to meet the specific needs of newcomer immigrant students with limited literacy backgrounds (Short, 2002). They also are critiqued for only focusing on English language skills at the expense of the native language(s) and using curriculum devoid of grade-level content. Pull-out ESL programs are critiqued for causing children to miss crucial experiences in the grade-level classroom and for stigmatizing children, a problem any pull-out program faces (Kinsella, 1992; Thomas \& Collier, 2000). The irony is that when grade-level teachers place the responsibility for educating newcomers entirely on the shoulders of pull-out ESL services, the child is often ignored in daily classroom activities. Such programs and practices contribute to the social marginalization of immigrant students and their teachers (Freeman \& Freeman, 2001; Feinberg, 2000) and have also reinforced a school ethos that casts immigrant education as a separate, specialized school function (Adger \& Peyton, 1999). Subsequently, the achievement gap between immigrant students like the Hmong and mainstream students may grow even larger, accentuated by the systematic tracking of students in programs which are entirely separate from the rest of the school. Thus, some of the programs designed to educate ELL students in mainstream classrooms actually may lead to academic and social marginalization.

\section{The Separate Approach}

Concerned about the negative consequences of integrated approaches on newly arrived immigrant/refugee student populations, schools around the United States have turned to alternative schooling options, such as the "newcomer program" (Feinberg, 2000; Jiang \& Kuehn, 2001). Newcomer schools can be "warm and sheltering spaces in which to care for and educate the sojourner" (Feinberg, 2000, p. 224). While there are many variations, newcomer programs are typically one-year programs designed to offer a welcoming educational environment for students new to the United States. They have goals of fostering rapid language acquisition (in English, or sometimes in both English and the native language), acculturation, and selfconfidence about schooling before students begin attending mainstream schools (Short, 2002). Newcomer programs frequently have specially designed courses for the type of students they serve. For example, the TLC model mentioned in this paper focuses not only on emergent literacy skills but also on school readiness skills that help students grasp the overall nature of learning and of the classroom work expected of them. Students new to the country and/or to school use this type of specialized newcomer program as a place of transition before they join the larger school programs. A newcomer program generally allows for consolidation of staff and resources. And because every student is an immigrant-many who come from limited literacy backgrounds-the academic and social environment often feels welcoming and safe for students.

Several important structural features lie behind successful newcomer programs. Research has shown the benefits of programs operating in a "family-" or "house-" like structure, where students are shared by a certain group of teachers (Lucas, 1992). This kind of environment facilitates integration of instruction and content, provides more opportunity for teacher 
collaboration and shared decision-making, and gives more academic and nonacademic support to students. In addition to maintaining strong relationships between school staff and students, productive newcomer programs actively maintain ongoing and guided parental involvement and foster links between newcomers and other students. In terms of curriculum and instruction, strong newcomer programs focus on initial literacy development and language development through a content-based curriculum, and explicitly address cultural orientation (Lucas et al., 1990; Short, 2002). When feasible, class is taught with the use of the students' native language(s) in order to accelerate learning (Hertzberg, 1998). Evidence suggests that when students' native language(s) are used in classrooms, students have access not only to acquiring English language skills at a faster pace, but also have access to valuable content they might not have had in an English-only learning environment (Lucas, 1992; Thomas \& Collier, 2000). Native language retention and acquisition are related not only to academic achievement but also to success with acculturation and sense of ethnic pride and continuity with their parents and others from their place of origin (Gibson, 1998; Olsen, 1998, 2000).

Newcomer programs are not without controversy. Some feel that newcomer programs are too isolating and do not provide enough opportunity for students to interact with English speaking peers (Feinberg, 2000). Furthermore, especially when newcomer programs are not bilingual, students may not be given the exposure and access to core curriculum courses and activities open to students in regular schools. This has serious legal implications. The Office for Civil Rights of the U.S. Department of Education has found discrimination based on national origin and failure to offer students equal access to the district's curriculum. ${ }^{6}$ In their review of research findings of ELLs at risk, Genesee and colleagues (2005) found an "overarching need for sustained, theory-driven programmatic research that aims to build and test models of effective teaching and successful learning in school settings with ELLs" (p. 377).

Newly-arrived immigrant and refugee populations with limited literacy backgrounds, like the Hmong newcomers of this study, are at greater risk for school failure than other immigrant populations. The present study aims to contribute to the current knowledge about newcomer programs at the elementary level by exploring two programs that sought to meet the academic needs of newly-arrived Hmong newcomers to St. Paul, Minnesota during the 2004-2006 school years. One program, the Transitional Language Center (TLC), taught the newcomers in a separate program while the other, the Language Academy (LA), taught the newcomers in a classroom with both immigrant and native English speaking students.

\section{Program Descriptions}

Knowing the risk of being accused of segregating students based on ethnicity, the SPPS District boldly crafted a separate program for the Hmong newcomers within five elementary schools. SPPS school personnel also were aware of the fact that Hmong newcomers had limited formal education prior to arrival in Minnesota. They hoped that they could meet the specific needs of hundreds of Hmong newcomers in their district without falling into the trap of marginalizing the program, the students, or their teachers. Some of the key instructional principles guiding the TLC model include:

1. The native language and culture are welcomed in the classroom and serve the student for learning both English and content.

2. Content and language are learned together, therefore there was no pull-out instruction. 
Bigelow, Basford and Smidt: Supporting Hmong Newcomers' Academic and Social Transition

3. Placement was not determined according to age; therefore, classes were multi-age and multi-grade. Students were permitted to be in classes with family members.

4. Collaboration between professionals with different areas of expertise results in better learning environments; therefore, ESL and grade-level teachers co-taught.

5. Housing the program within a school eases the transition into a mainstream class and affords contact with children who are not newcomers.

6. Placement in the TLC was temporary and led to another appropriate program that also had services for English language learners.

To meet staffing needs, the TLCs drew from the large number of Hmong teachers and Educational Assistants (EAs) already employed in the district.

The LA model shares many of the philosophical underpinnings with the TLCs, such as valuing native language and culture, clustering children with similar language backgrounds, and teaching language through content. However, the LA model differed structurally from the TLC model in a few essential ways:

1. Newcomers are integrated into classes with other children, including native or nearnative English speakers. Some children in the LA programs may be newcomers and some may have been born in the United States. The children in the TLCs consisted of only Hmong newcomers.

2. The LA model uses some pull-out to teach "survival" language skills, and basic literacy and numeracy skills, if needed. The ESL teachers and the EAs are mainly charged with this work.

3. The ESL teachers work with two or three different teachers every day. The ratio in an LA is one ESL teacher to 27 children, while in other classrooms with ELLs of higher levels, the ratio is typically 1 to 55 .

4. There are far fewer bilingual Hmong staff members in LA sites than in TLC sites.

Neither the TLC nor the LA program, however, was truly bilingual in the sense that neither intended to promote the development of both English and Hmong. For example, bilingual staff members in the TLCs were expected to use both languages throughout the day, but the use of Hmong was expected to diminish over time and instruction was expected to be mostly in English by the end of the school year. This practice was thought to help children accomplish greater gains in English and prepare them for a classroom where English is the only language of instruction. Thus, the transitional nature of the program is a key feature, and, as will be shown later, is forefront in teachers' minds as they move away from using Hmong and into using English. ${ }^{7}$

The TLCs are more expensive to run than the LAs because they required separate space, more teachers, additional teacher development and a separate, specialized curriculum. Therefore, in addition to wondering if it was helpful for the children to be in the separate, segregated program, the District also wanted to know whether the differences were dramatic enough to warrant similar programs in the future. The specific questions that this paper will explore are the following: What program features do educators see as important for meeting the needs of elementary Hmong newcomers? How do the TLC and LA programs compare? 
Bigelow, Basford and Smidt: Supporting Hmong Newcomers' Academic and Social Transition

\section{Methodology}

The participants in this study consist of grade level teachers, ESL teachers, and EAs from three TLC and two LA sites (see Table 1).

Table 1: Participants

\begin{tabular}{lccc}
\hline \multicolumn{1}{c}{ Site } & Grade Level Teacher & ESL Teacher & EA \\
\hline 3 TLC Sites & 3 & & 3 \\
Bilingual Hmong & 3 & 0 & 0 \\
Not Bilingual Hmong & & 3 & 2 \\
\hline 2 LA Sites & 0 & 0 & 0 \\
Bilingual Hmong & 3 & 3 & \\
Not Bilingual Hmong & & & \\
\hline
\end{tabular}

Participants were chosen by the researchers from a list provided by the District that indicated: (a) the staff member's role in the program (ESL teacher, grade level teacher or EA), (b) whether or not they were bilingual in Hmong, (c) what license(s) they held, and (d) how many years they had been teaching. Using these criteria, the researchers assembled a diverse pool of 20 staff members to interview that would represent a range of perspectives. The interviews were approximately 40 minutes long and followed a semi-structured protocol that allowed for followup questions. The topics of the interview included questions about the program, students, curriculum, collaboration, training, teaching strategies, parental involvement, and transition into and out of the program. ${ }^{8}$

Table 2: Codes Listed in Order of Frequency

\begin{tabular}{|l|l|}
\hline 1. Description of children & 15. Influx of new students during the academic year \\
\hline 2. Teacher experiences & 16. Hmong cultural training \\
\hline 3. Curriculum - description & 17. Popular classroom activities \\
\hline 4. Curriculum - challenges & 18. Transitions - factors that help \\
\hline 5. Transitions - mainstreaming & 19. Contact with other children \\
\hline 6. Transitions - problems & 20. Curriculum - teaching strategies \\
\hline 7. Parents - communicating with them & 21. Bilingual - children \\
\hline 8. Previous schooling & 22. Content-based instruction \\
\hline 9. Curriculum - connections to culture & 23. Successful engagement of children \\
\hline 10. Bilingual teaching & 24. Co-teaching \\
\hline 11. Refugee camp experience & 25. Teacher passion \\
\hline 12. Bilingualism & 26. Different refugee population \\
\hline 13. Parents and coming to school & 27. Unsuccessful engagement \\
\hline 14. Parent involvement & 28. Curriculum - successes \\
\hline
\end{tabular}

After all interviews were transcribed, data were analyzed using NVivo (QSR International, 2005), a software designed specifically to organize qualitative data. As illustrated above, the interviews were coded according to the participants' knowledge of Hmong, role in the program (grade level teacher, ESL teacher, EA), and site (TLC, LA). Open coding resulted in category construction (Merriam, 1988) which offered a way to summarize all of the topics that arose in the interviews. Table 2 lists the codes in descending order so that the reader can see which topics came up in the conversations as well as which received the most attention in the interviews, across all sites and with all staff members. 
Next, data were sorted according to program type (TLC or LA) and according to the role of the staff member (grade-level teacher, ESL teacher, EA). In other words, it was possible at this point to re-read all of the data from the TLCs and LAs according to the perspective of the participants' role in the programs. For example, researchers re-read all of the interviews from all of the ESL teachers in the TLCs. It was from this second pass through the data that the themes related to bilingual education emerged as a key element that fostered success for the Hmong newcomers.

\section{Results}

Conversations with Saint Paul Public Schools staff show that the Hmong refugee newcomers from the Wat were welcomed in many ways into both TLC and LA classrooms. Teachers and educational assistants had positive views toward the children and worked very hard to help them adjust to their new environment. Most of the teaching staff in both programs had had long involvement with the Hmong community. They were very knowledgeable about working with English language learners, the Wat refugee camp conditions, and the challenges newcomers face. Although all of the teachers were clearly well qualified to work with the Hmong newcomers, key programmatic differences emerged in the data that indicated that overall the TLCs were better able to meet the needs of the Hmong newcomers. These differences are revealed through how the educators talk about the children in general, the program and school they teach in, and in their beliefs about language learning and transitions to a U.S. elementary school.

\section{The Children}

The LA and TLC teaching staff members (i.e., ESL teachers, grade-level teachers, and educational assistants) were all delighted to have the opportunity to teach the Hmong newcomers from the Wat. Many shared that they had had newcomers with limited formal schooling in their classrooms before and that this type of learner was not a new experience for them. They all actively sought out information about the children with regard to prior schooling and Hmong or Thai literacy skills. However, while the dispositions of the teachers seemed similar in the two programs, the ways the teaching staff described the Hmong newcomers showed striking differences. While staff from both programs shared stories about the newcomers' challenges, staff from the TLCs had many more details about the academic and emotional struggles or needs of specific children (e.g., social isolation, unfamiliarity with food, suspected learning disabilities). The lengthy stories about individual children by both teachers and EAs revealed the close and constant contact staff had with the children. The LA staff members who did not speak Hmong were also concerned about the children, but their stories seemed to lack details and depth, in comparison. They noted that the Hmong newcomers were "in shock" but were not able to describe the children's specific worries, stressors, or their eventual transition.

Particularly salient in the conversations with the staff from both programs were the differences in how they described the children. While both programs mentioned the initial adjustment challenges, the TLC teaching staff generally described the children as bright and vivacious. Examples of their descriptions of the children are as follows:

- "When they came to us they were very eager to learn." 
Bigelow, Basford and Smidt: Supporting Hmong Newcomers' Academic and Social Transition

- "They learn quickly and are willing to do just about anything for you. They're very complacent and very easy to work with."

- "I'm surprised at how fast and well they have adapted ... You will never be able to tell that they were newcomers."

- "We never thought we were gonna come this far for sure."

- "They love to learn new things. They love to share and they ... love me ... they love the teacher who is also in there with me."

- "They ask for homework. A lot of them ask if they can sleep over at school."

The data from the staff at the LA sites were quite different. They often described the Hmong newcomers as shy and fearful. Examples of these descriptions are the following:

- "Very shy ... very reserved ... real frightened ... real afraid."

- "They seemed more ... hmm ... a little just overall ... a little more hesitant ... a little less willing to take risks. I didn't notice many kids who were initially kind of outgoing."

- "I mean ... they're terrified of a ton of things and bewildered."

- "They don't feel comfortable or they don't have much confidence. Then they are just kind of learning from the inside and not talking."

One LA site, the one that requested to have all the Hmong newcomers together and where there was consistent and abundant Hmong EA involvement, described their Hmong newcomers a little differently from the others:

- "Similar to the students - just any child at that age."

- "They like to play and they like to talk with their friends ... and [laughing] they're ... you know ... enthusiastic about trying things out and using new materials."

These descriptions are much more like the TLC descriptions of the children and are likely due to the bilingual Hmong EA support. From this data, it is fairly easy to conclude that the Hmong newcomers felt more comfortable when they had Hmong-speaking peers and teachers, and that the classrooms that offered this, TLC and LA alike, had the potential to create a welcoming and productive learning environment.

\section{Bilingual or "Bilingualish" Program Features}

The TLCs could guarantee a bilingual learning environment while the LA could not. The presence of at least one bilingual teacher and a student body made up entirely of Hmong newcomers allowed Hmong language to be widely used without the risk of excluding a child of a different native language. On the other hand, in the LA program, bilingual staff members were not always available, and the Hmong newcomers were the minority in multilingual classes. In the LA classes, there were small clusters of Hmong newcomers or even single Hmong children in multilingual classes.

The interview data with LA staff showed that it was difficult to plan for the integration of the Hmong newcomers into the LAs because the assumption was that they would be enrolled mostly in TLC programs. One LA teacher said, "They literally just kind of dropped out of the 
sky ... I mean we pulled it together in just a matter of a week or two." The outcome of this was that the LA classes were generally unable to tailor any of the curriculum or instruction to the needs of the Hmong newcomers due to little bilingual support and lack of prior notice. In fact, some of the other LA students had to make up for this gap. One teacher said that a bilingual Hmong child in her classroom did so much interpreting that the teacher felt she should be paid for her work. Due to these challenges, the LA staff used pull-out services where "survival English" was taught as well as basic literacy skills. One TLC teacher empathized with the teachers in the LA settings because the LA teachers have "one kid so far [behind] that he or she doesn't know anything that's going on when the teacher has the responsibility with the other 20 children," a sentiment that harkens back to the teacher previously quoted in the study by Chang (1990). The same TLC teacher pointed out that the LA Hmong newcomers "would just be lost without support with the language."

However, one of the two LA sites we visited was proactive. ${ }^{9}$ These teachers reported going to the administration of the school and saying, "If any kids come from the camp, we want them in this room." This action resulted in one teacher from this site having three Hmong children in the same classroom. The teachers in this classroom reported that the children quickly bonded and supported each other. Many TLC teaching staff members mentioned bilingual support as the feature of the program that was particularly good for the Hmong newcomers because, "they're very smart kids ... you know ... but, the only thing is, they lack the language."

Over the course of the academic year, staff in the TLC were supposed to gradually reduce the amount of Hmong spoken in the classroom. Most teachers agreed that this was an important way to prepare the newcomers for the following year when bilingual support would not be guaranteed. But one grade-level TLC teacher was frustrated by her Hmong-speaking colleague, an ESL teacher, who continued to use Hmong for basic instruction and interactions until the end of the school year. Another teacher said their program was "bilingualish" but she was uncertain exactly how and when to use Hmong in ways that reflected best practices. She said, "I don't know about the bilingual piece." She said she would have liked more training "in terms of what really is best."

\section{The Inevitability of Mainstreaming}

For academic and social reasons, many of the TLC staff members felt that it would be beneficial for students to have the opportunity to stay in the TLC for another year, particularly those who arrived later in the academic year. One EA believed that it would be good to keep the Hmong newcomers for many years in self-contained classes or in a program where they could be together for half of the day. He said that if they were put in with "regular" kids they would be shy and risk not being understood by peers and the teacher. Unfortunately, this fear is welldocumented in educational research that shows that the ways immigrant youth often have lower academic achievement and high drop out rates (e.g., Grant \& Wong, 2003; Suárez-Orozco \& Suárez-Orozco, 1995).

One TLC teacher said that her students were also ready for the LA setting, not the mainstream class. Her reason was that she felt that her students had enough social language and were ready for more academic challenges despite the fact that they were far from being at grade level. Luckily, this district has many LA classrooms for the TLC students to transition to and a highly qualified ESL teaching force that routinely works with grade-level teachers to develop immigrant children's language and content learning. Given the complexity of the issues, it is no 
surprise that teachers' opinions were mixed and ranged from full and immediate transition into the English-only mainstream to staying indefinitely in a separate program for Hmong students. These results illustrate how the separate versus integrated issue is widely debated in the profession among caring and competent educators, Some falling on the side of Feinberg (2000) who argues that "any plan that increases rather than decreases racial, ethnic, or linguistic isolation in our schools should be reviewed in every detail" (p. 225) and others who see the cultural, linguistic and educational benefits of a bilingual program for same-language students. Irrespective of the teachers' opinions about the optimal length of the newcomer programs, the fact remains that in this district, like so many others, the Hmong newcomers will likely spend most of their schooling in multicultural, but not bilingual classrooms.

\section{Bilingual Language Support and Learning}

As we have shown, the difference in native language support between the programs is a key distinguisher. Across programs, it seems that the Hmong and Thai languages, when used, were used in the oral (i.e., speaking and listening) modes. Some TLC teachers, at the older levels with students who had some prior schooling, periodically facilitated the children's use of Hmong or Thai writing. Teachers reported that when the native language was used, it was used to instruct, to explain and to clarify with the ever present push toward more and more English language comprehension and use. The TLCs were structured to use the students' linguistic resources while similar support in the LAs was not assumed. When educators use the students' native language across academic and social contexts, and view the native language as a resource, the learning community becomes more inclusive and productive (e.g., McKay \& Wong, 1996).

The lack of children's access to bilingual staff in the LAs was due to slow hiring of EAs, failure to place children with bilingual teachers, and siphoning off of Hmong EA resources to address the needs of other children perceived as more needy. One teacher said, "I was really frustrated when the Hmong kids came. I was happy to have them, but for the longest time we had no interpreter." On the other hand, when there was bilingual staff available for generous portions of the day in a LA, the staff was much more confident that language and content learning were progressing normally.

The effect of having bilingual support on the children was dramatic, as reported by both the TLC and the LA staff. One EA said that the native language helped the children "feel confidence that even though they don't understand ... we can explain to them in their own language and help them." This EA went on to say that when "they have their own language, they learn better or they're quicker in another language." A TLC teacher said that it was very important to maintain their native language and that Hmong children (in reference to the Hmong language) "tend to lose a very good thing." Another TLC teacher said the children's native language was "respected by using it ... being able to use it ... being able to speak freely in it and ask questions in it." At the same time, there was some tension among TLC staff, about the use of native language. One TLC teacher felt the children were relying too much on native language support and they were ready to be in a more English-speaking environment. She thought this would be good for developing their English skills because students were using Hmong "as a crutch more than they actually needed it." A Hmong teacher said that she knew she needed to move into speaking more English, but that if she did so, "anyone could be their teacher" and the benefit of having a Hmong teacher seemed to be diminished. She went on to explain her ambivalence: 
Bigelow, Basford and Smidt: Supporting Hmong Newcomers' Academic and Social Transition

I've pondered over it ... you know ... I speak to other colleagues and we ... we kinda feel like we're . . . hmmm ... I don't know what's the word to explain ... but it feels ... feels bad ... you know that ... well why are they saying this and why ... I mean the purpose is to help these kids.

She felt that it was important to use the native language to teach the concept, and then later "the language will come," so the policy to ease out of Hmong into English was a difficult choice for her.

Although native language support in LA classrooms was irregular, one teacher noted that when Hmong staff members were present, children would engage more in classroom activities. He observed that when Hmong staff talked to students about the camp, or showed pictures from the Hmong news, the students "would just talk up a blue streak." This is something that is only possible to do in the native language, given the students' low level of English proficiency. Not only did the students talk more when given an opportunity to interact with a Hmong adult, but native language support helped learning as well. For example, an ESL teacher at a LA school noted that it would be good to do higher level questions and research with a big project, but that this was only possible with native language support. She said the EAs "are excellent at ... conveying concepts in Hmong and kids ask questions."

While it is a common belief among educators and others that less native language use will result in higher academic achievement, the contrary is actually true (Cummins, 1981). Welcoming the native language(s) of immigrant children into the social and academic realm of schooling has the potential to make them feel less socially marginalized and allows them to learn difficult concepts in their dominant language. In other words, research shows that the native language is never a "crutch" but rather a resource.

\section{Students' Experience in the Curriculum}

Culture is a difficult concept to define and articulate in general, and the teaching staff in both LA and TLC programs struggled with the question of how "Hmong" and "American" culture were integrated into the curriculum. Many teachers could not cite any cultural references in their classrooms with the rationale that they were focusing on the transition into a U.S. school culture and academics - "the American way of teaching." That said, the descriptions of culture integration in the LA were mostly surface level (e.g., holidays, dress, cultural artifacts, traditional customs, setting a table in the United States, food). This approach to making children feel "welcome" may actually marginalize them more than doing nothing at all because their culture is reduced to stereotypes (Gitlin et al., 2003).

The data revealed much richer integration of culture in the TLCs. For example, one TLC teacher explained that the Hmong language was used and that the lived experiences of the children was elicited and honored on a daily basis. Another TLC teacher said that the children "are living their culture pretty much in our classroom" meaning that children are allowed to "be Hmong" in all they do - through their language use, their art, their games, their interaction with teachers and peers, among other things. TLC teachers told of how cultures were sometimes compared. For example, in a thematic unit on houses, the class built American, Hmong, Thai, and traditional Native American houses. Hmong culture was included in another class activity when the group made a Venn diagram illustrating the differences and similarities about having a 
baby in Thailand and in the United States. The teacher said the activity "was revealing to them because some of the things they didn't understand about having a baby here where the mother takes six weeks off and then goes back to work. In Laos there are certain rituals and customs that they have to go through." Culture was included on another occasion when two classes made a traditional Hmong story quilt together with the help of a grant. "Each class wrote a story and then every kid was responsible for a square of the quilt based on a certain portion of that story."

The refugee camp experience became part of the curriculum in numerous TLC classrooms. One TLC teacher invited the students to bring possessions to school that they had from the camp or from home and talk about their memories of the camp. Another class did a unit on chickens. The teacher said, "they've all had chicken and rooster experiences and they talked a lot about those experiences." One class drew a map of the refugee camp-where they lived and where their friends lived and the geographical features of the camp. This classroom welcomed the students' stories of the camp. This led to students telling the class where there were ghosts. The teacher said she knew that "many of our kids have had tragic, tragic lives. One day a student woke up and looked out the window and someone was hanging from a tree outside his window." She said that they tell about these experiences "without batting an eye."

These examples suggest that the curriculum in the TLC was "permeable" (Dyson, 1993). Children were able to use some of their previous experiences in their new classrooms. In reference to student behavior and culture, one TLC teacher advised:

You need to be mindful of culture because the kids seem to be from a culture where they just really like to talk to each other and sometimes they are talking to understand what I'm saying. But sometimes they're just talking and they are really vocal and it can be quite overwhelming-just the noise level in our room. It's been one of the biggest differences - just to get used to this need to be talking. It's just how they are.

Another TLC teacher was sensitive to the students' collectivist culture and joy in doing things together. She told about how one day they were playing Hmong music: "All the girls would dance and the boys were dancing which I haven't really seen before. They would dance and sing and they knew a lot of songs."

The staff from the LAs had few examples about this type of integration and recognition of culture. One teacher expressed the desire to have information about Hmong heroes. Another teacher said that all they received from the district was a Hmong dictionary. She said, "I looked through it ... I put it on the shelf and there it stayed."

The findings reported in this section speak to the potential a bilingual and culturally homogeneous classroom has for creating a culturally relevant curriculum and a learning community that can share common cultural codes while making the transition to a new culture. The data reminds educators to be mindful of how students" "culture" is brought into the classroom such that it will not be reduced to stereotypes but rather allowed to emerge in studentgenerated and organic ways.

\section{Interaction with Peers}

Finally, one of the often-cited problems with newcomer programs is that they isolate refugee students from peers who have been in the country longer or who were born in the host country. A TLC grade-level teacher shared that "a lot of parents were concerned that just having them with 
students from ... the camp would decrease their chance of learning more English" due to lack of contact with English-speaking peers. This teacher said that the TLC "needs to think about this because parents expressed that concern."

Indeed, one of the LA program's strengths was that it brought newcomers into contact with English-speaking peers immediately. In support of the LA model, one teacher said:

I think students have been getting ... a good amount of time in the classroom being exposed to all of those English speaking peers and that level of academic rigor in the curriculum and seeing what's going on and what's expected of them and how they should be progressing ... and with being pulled either to another part of the classroom or being pulled out and receiving a parallel or a scaffolded curriculum. I think ... we've had Language Academy here for many years ... like seven or eight. So, I think it works pretty well.

This comment speaks to the flexibility of the program and the fact that it was "tried and true." This teacher went on to admit that she could do so much more with native language support and complained that it was late in coming to their school with regard to the Hmong newcomers. Another teacher believed that the best thing about her building "is that it's sort of like a little microcosm of the entire world." She said that she "likes the mainstream over the TLC. I don't know that much about the TLC, but I kind of like the mainstreaming here. I think they can learn things so much quicker when they are just immersed with everything at one time." This was softened with the remark "especially if they have other kids who speak their language in the school"- Suggesting once again the potential benefit of native language interaction for learning.

The TLCs, while engendering close-knit, warm, family-like classrooms, did struggle with ways to meaningfully bring the newcomers into contact with other children in the school. The students "generally have lunch together ... recess ... but usually our kids hung out and stay with their own class and not really ... hmmm ... play with other kids." Another TLC teacher said:

There should have been some forethought in how to have our students interact with the other kids this year because really there was no time during the day that they were ever with the other children. We kept hearing during the orientations, "oh, they'll be out in the playground and they'll be in the lunchroom. Well of course they were but they weren't together. They would never have naturally gone and hung out with those kids. It just naturally would not have happened. And it didn't happen.

Recognizing this as an issue, some TLC teachers organized activities that brought the students together. These activities included establishing a reading buddies program in which the newcomers went to a higher grade for tutoring, singing activities for the Hmong New Year, and going to the zoo. The fact that there were Hmong children throughout the school facilitated activities such as these in the TLC schools. Obstacles to doing more of these types of activities were pressures of testing, not having a co-teacher, and pressures to do as much "catch up" with the children as possible to prepare them for the following year.

Worth noting was the report by one TLC teacher that at her school, some teachers seemed to react negatively to the program and the children. The teacher said that she "sensed that there was a separation." They called the Hmong children "your students" as if they were not part of the school, and "the buzz in the school was that our children needed to be tamed." So, the way the 
program was set up seemed not only to separate the Hmong children from other children in the school, but also separated the program from the school and even fostered the dehumanization of the students, at least in the eyes of some.

\section{Discussion}

The results show that serving newcomers with little prior schooling is a complex task filled with instructional, curricular, and institutional challenges as well as human emotions (Hargreaves, 1994; Igoa, 1995). Conversations with all of the staff show a clear desire to provide quality education for the newcomers. However, the TLC, as a program model, had the potential to have many advantages over the LA model due to the bilingual support afforded the Hmong newcomers. Although the isolation of the children may have been an initial concern, it does not seem that this is evidence enough to discontinue the TLC model for newcomers of the same native language background. Some of the most compelling evidence that the TLCs were better for the Hmong newcomers was revealed in the descriptions of the children. These findings, however, were repeated, albeit to a lesser degree, in a LA that had consistent bilingual support. Therefore, the data indicate that, when possible, newcomers should be afforded significant contact with bilingual staff members to ease the transition to a new country, and avoid interrupting schooling due to a complete lack of understanding of content delivered only in English.

Bilingual staff members proved to play a crucial role for the close monitoring of the adjustment and learning of individual children, which is an essential component of an effective support system for newcomers and their families. Bilingual staff members play a key role in revealing to newcomers all of the aspects of mainstream classrooms that are implicit such as discipline expectations, classroom routines, and taking turns according to school norms. This is often referred to as the "hidden curriculum" (Jackson, 1968). Decades of research in bilingual education would concur with this finding for children across a range of linguistic and cultural groups (Willig, 1985) and ample access to bilingual educational assistants has been an important feature in other schools in the district in the past (Watson, 2001). They provide a bridge between languages and cultures and between parents and schools.

The bilingual environment described by the teachers opened the door for a much more humanizing pedagogy (Freire, 1970). Teachers spoke of creating a family among the members of the classroom centered on care for each other. This is in contrast to the descriptions of the children from the LA classrooms, which seem to suggest that the Hmong newcomers were at the edges of the classroom community. The bilingual classrooms also welcomed a range of cultural and social practices. The TLCs seemed to be poised to offer a humanizing pedagogy that values the students' background knowledge, culture, and life experiences (Bartolome, 1994) due to the bilingual nature of the learning environment.

The classrooms with Hmong speaking teachers also allowed children to use language in a wide range of ways. This is very beneficial for children as they learn how to talk and act in school as well as how to learn through English. The opportunity to engage with adults in Hmong on academic topics has great potential for scaffolding academic language in English. Furthermore, the cognitive development of the children is enhanced through the use of two languages because the presence of bilingual teachers allows them to work with age-appropriate academic content bilingually while learning English. This is much more engaging for children 
new to school compared to a monolingual program where the depth or complexity of the content is limited by the level of English language skills the children possess.

\section{Recommendations and Conclusion}

Others can learn and benefit from the TLCs. For example, many TLC staff members were able to integrate Hmong culture and the students' past experiences in very thoughtful ways. They could be asked to integrate ideas into the district curriculum which could be used as resources for nonTLC staff in how to teach Hmong newcomer students. In addition, the Hmong educational assistants often knew things about the children that nobody else seemed to know. It would be worthwhile for them to have a venue for sharing their insights about the students more frequently with the teachers they work with as well as in professional development settings.

In terms of professional development, TLC staff could have benefited from some training in bilingual education so that they can make more thoughtful decisions about when and how to use each language. Furthermore, conversations about the philosophy of the program may have lessened the level of disagreement around language choice and use. They could have based some of these choices on literature from the field. The TLC model availed newcomers of a bilingual transition to American schooling. Nevertheless, the TLC model should not be mistaken for a larger schooling system that ultimately, implicitly or explicitly, promotes subtractive bilingualism - In this case the loss of Hmong language skills (Wong-Fillmore, 1991) and an assimilationist educational philosophy (Gibson, 1988). While the TLC model aimed to shift the language of instruction gradually to more and more English, the programs the Hmong newcomers were destined for did not guarantee any bilingual support. A subsequent alternative to a mainstream program for this population may be a two-way dual immersion program (Cloud et al., 2000). This type of program would alternate the language of instruction during the day between Hmong and English and be comprised of 50\% Hmong newcomers and 50\% native English speakers, presumably heritage speakers of Hmong who would like to recover some of their language loss. This is entirely feasible at this point in time given the high numbers of newcomers at the elementary level and the availability of qualified bilingual teachers. The issue may hinge on whether or not the parents and other stakeholders would support such an approach.

In conclusion, this research, although limited to conversations with teachers and educational assistants, illustrates how a program that uses the native language of the children as well as bilingual teachers has many positive, possibly long-term benefits. Because of the bilingual teachers and educational assistants, children were able to engage in content learning, experience early success in school activities, draw from past experiences, learn English and interact fully with peers and adults all the while. The TLC program model should serve as a positive example of how to support the transition to school and promote the academic success of a newcomer group. The challenge now is to devise programs that will sustain the Hmong children's new-found love of school and value their native language abilities well into their educational futures. 
Bigelow, Basford and Smidt: Supporting Hmong Newcomers' Academic and Social Transition

\section{Endnotes}

${ }^{1}$ Data from the 2000 Census found that Minnesota is home to the second largest Hmong population in the United States $(41,800)$, and the Minneapolis-Saint Paul metropolitan area has the largest Hmong population of any metropolitan area in the country $(24,389)$. In October of 2005, the Saint Paul Public School District reported 22,737 children who speak Hmong at home. In 2006, the number dropped to 10,252 (Minnesota Department of Education, 2005, 2006).

${ }^{2}$ Educational opportunities at the Wat were very limited. Hmong families lived in a fenced off, gated, and guarded area around the Buddhist monastery. School and work opportunities outside of the camp were limited, thus children lived in an environment that was largely culturally and linguistically Hmong. A report prepared by a delegation from St. Paul, MN to learn about camp conditions found that children between the ages of 6 and 18 had an average of two and a half years of education, with boys typically receiving more education than girls (Toosi, 2004).

${ }^{3}$ District personnel knew that Hmong parents often followed the advice of Hmong family or friends who were more familiar with the educational system, rather than making an informed decision of their own. They were likely to trust the school in the way their children were educated (see Ngo, this volume) or were never told what the nuances were between the Language Academy Program and the Transitional Language Center Program.

${ }^{4}$ By literacy we mean alphabetic print literacy and the ability to encode and decode text as well as the academic literacies children gain in formal school settings.

${ }^{5}$ Submersion is a term in the field meaning "sink or swim," full inclusion into Englishonly instruction with native English speakers (referred to in this paper as "mainstream" students). "Inclusion" or "immersion" can also be a euphemism for a program that is actually submersion because of the lack of services offered ELLs (Wolfe, 1999).

${ }^{6}$ A number of well-known cases (e.g., Lau v. Nichols (1974), Castañeda v Pickard (1981)) guide design features of newcomers schools such as the following: a) enrollment is voluntary, b) a trajectory for exiting the newcomer school is clear, c) quality of facilities, staff and courses is comparable to other schools in the district.

${ }^{7}$ The TLC program offered students opportunities to transition in other ways as well acclimating to the U.S. classroom environment, school food, etc., but the data suggest that the issue of transitioning to English was one of the key ways the TLC was a transitional program. It is relevant to note that the shift to an English-only classroom is not necessarily an essential quality of a newcomer program. Many programs for immigrant children maintain use of the native language throughout their schooling to promote additive bilingualism, and pride in the native culture and language. Bilingual education has been shown to promote academic achievement rather than deter it (e.g., Willig, 1985).

${ }^{8}$ The fact that we were only able to use interviews as data proved to be a limitation of the study. The constraints of the study were such that class observations and interviews with the children were not possible. These additional types of data would have made the findings of this study stronger through triangulation.

9 This is the same site previously mentioned where the LA teachers described the newcomers in ways similar to the TLC teachers' descriptions. 
Bigelow, Basford and Smidt: Supporting Hmong Newcomers' Academic and Social Transition

\section{References}

Adger, C. T., \& Peyton, J. (1999). Enhancing the education of immigrant students in secondary school: Structural challenges and directions. In C. Faltis \& P. Wolfe (Eds.), So much to say: Adolescents, bilingualism, and ESL in the secondary school (pp. 255-271). New York: Teachers College Press.

Bartolome, L. I. (1994). Beyond the methods fetish: Toward a humanizing pedagogy. Harvard Educational Review, 64(2), 173-194.

Castañeda v. Pickard (1981). 648 F.2d 989, U.S. App. LEXIS 12063.

Chang, H. (1990). Newcomer programs: Innovative efforts to meet the educational challenges of immigrant students. San Francisco, CA: California Tomorrow.

Cloud, N., Genesee, F., \& Hamayan, E. (2000). Dual language instruction: A handbook for enriched education. Boston, MA: Heinle \& Heinle/Thomson Learning.

Cummins, J. (1981). The role of primary language development in promoting educational success for language minority students. In California State Department of Education (Ed.), Schooling and language minority students: A theoretical framework (pp. 3-49). Los Angeles: National Dissemination and Assessment Center.

Cummins, J. (1988). Second language acquisition within bilingual education programs. In L. Beebe (Ed.), Issues in second language acquisition: Multiple perspectives (pp. 145-166). New York: Newbury House.

Dyson, A. H. (1993). Negotiating the permeable curriculum: On the interplay between teacher's and children's worlds. Urbana, IL: National Council of Teachers of English.

Feinberg, R. (2000). Newcomer Schools: Salvation or segregated oblivion for immigrant students? Theory into Practice 39(4), 220-227.

Freeman, D., \& Freeman, Y. (2001). Between worlds: Access to second language acquisition (2nd ed.). Portsmouth, NH: Heinemann.

Freire, P. (1970). Pedagogy of the oppressed. New York: Continuum.

Genesee, F., Lindholm-Leary, K., Saunders, W., \& Christian, D. (2005). English language learners in U.S. Schools: An overview of research findings. Journal of Education for Students Placed at Risk, 10(4), 363-385.

Gibson, M. A. (1988). Accommodation without assimilation: Punjabi Sikh immigrants in American high schools and community. Ithaca, NY: Cornell University Press.

Gitlin, A., Buendía, E., Crosland, K., \& Doumbia, F. (2003). The production of margin and center: Welcoming-unwelcoming of immigrant students. American Educational Research Journal, 40(1), 91-122.

Grant, R. \& Wong, S. (2003). Barriers to literacy for language-minority learners: An argument for change in the literacy education profession. Journal of Adolescent \& Adult Literacy, 46(5), 386-394.

Grigoleit, G. (2006). Coming home? The integration of Hmong refugees from Wat Tham Krabok, Thailand into American society. Hmong Studies Journal, 7, 1-22.

Hargreaves, A. (1994). Changing teachers, changing times: Teachers' work and culture in the postmodern age. London: Cassell.

Hertzberg, M. (1998). Having arrived: Dimensions of educational success in a transitional newcomer school. Anthropology \& Education Quarterly 29(4), 391-418. 
Bigelow, Basford and Smidt: Supporting Hmong Newcomers' Academic and Social Transition

Hmong 2000 Census Publication: Data \& Analysis (n.d.). Hmong National Development, Inc. \& Hmong Cultural and Resource Center. Retrieved on November 25, 2008 from http://www.hmongstudies.org/HmongCensusPublication.html

Igoa, C. (1995). The inner world of the immigrant child. Hillsdale, NJ: Lawrence Erlbaum Associates.

Jackson, P. W. (1968). Life in classrooms. New York: Hold, Rinehart and Winston, Inc.

Jiang, B. \& Kuehn, P. (2001). Transfer in the academic language development of post-secondary ESL students. Bilingual Research Journal, 25(4), 417-436.

Kinsella, K. (1992). Moving from comprehensible input to "learning to learn" in content-based instruction. In P. A. Richard-Amato \& M. A. Snow (Eds.), The multicultural classroom: Reading for content-area teachers (pp. 46-68). New York: Addison-Wesley Publishing Company.

Lau v. Nichols. (1974). 414 U.S. 563, 94 S. Ct. 786.

Lucas, T. (1992). Successful capacity building: An analysis of twenty case studies (Phase III Report: Descriptive Analysis of Bilingual Instructional Service Capacity Building Among Title VII Grantees). Oakland: ARC Associates.

Lucas, T., Henze, R., \& Donato, R. (1990). Promoting the success of Latino language minority students: An exploratory study of six high schools. Harvard Educational Review, 60(3), 315-339.

McKay, S., \& Wong, S.-L. C. (1996). Multiple discourses, multiple identities: Investment and agency in second-language learning among Chinese adolescent immigrant students. Harvard Educational Review, 66, 577-608.

Merriam, S. B. (1988). Case study research in education: A qualitative approach. San Francisco: Jossey-Bass Publishers.

Minnesota Department of Education, Office of Information Technologies. (2005, 2006). Survey of language spoken at home. Retrieved November 22, 2008 from http://education.state .mn.us/MDE/Data/Data_Downloads/Student/Languages/index.html

Olsen, L. (2000). Learning English and learning America: Immigrants in the eye of a storm. Theory into Practice, 39, 196-202.

Olsen, L. (1998). Made in America: Immigrant students in our public schools. New York: The New Press.

QSR International. (2005). NVivo [Computer software]. Victoria, Australia: QSR International.

Short, D. J. (2002). Newcomer programs: An educational alternative for secondary immigrant students. Education and Urban Society, 34(2), 173-198.

Suárez-Orozco, M. M., \& Suárez-Orozco, C. (1995). Transformations. Stanford, CA: Stanford University Press.

Thomas, W. P., \& Collier, V. P. (2000, November). Language minority student achievement and program effectiveness. National Clearinghouse for Bilingual Education, 18(5), 4-5.

Toosi, N. (July 10, 2004). A final wave of immigrants: New chapter in a saga of exile, independence. Milwaukee Journal Sentinel. Accessed October 19, 2007: http://www.jsonline.com/story/index.aspx?id=242852.

Townsend, J. \& Fu, D. (2001). Paw's story: A Laotian refugee's lonely entry into American literacy. Journal of Adolescent \& Adult Literacy, 45(2), 104-114.

Um, K. (2003). A dream denied: Educational experiences of Southeast Asian American youth. Washington DC: Southeast Asia Resource Action Center. 
Bigelow, Basford and Smidt: Supporting Hmong Newcomers' Academic and Social Transition

Walker, P. (2004). American Paj Ntaub welcoming Wat Tham Krambok refugees to Minnesota. Minnesota Department of Health. Retrieved July 30, 2007 from http://www.health.state.mn.us/divs/idepc/refugee/ihtf/watmay04.ppt.

Watson, D. C. (2001). Characteristics of Hmong immigrant students: The response of a university/elementary school collaboration. Childhood Education, 77(5), 303-307.

Willig, A. C. (1985). A meta-analysis of selected studies on the effectiveness of bilingual education. Review of Educational Research, 55(3), 269-317.

Wolfe, P. (1999). Changing metaphors for secondary ESL and bilingual education. In C. Faltis \& P. Wolfe (Eds.), So much to say: Adolescents, bilingualism, and ESL in the secondary school (pp. 83-102). New York: Teachers College Press.

Wong-Fillmore, L. (1991). When learning a second language means losing the first. Early Childhood Research Quarterly, 6, 323-346.

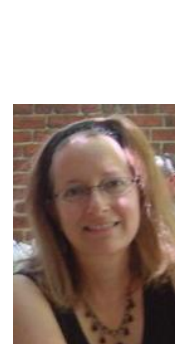

\section{About the Authors}

Martha Bigelow is an Associate Professor at the University of Minnesota in the Department of Curriculum and Instruction. Her research, teaching and community engagement activities focus broadly on second/foreign language learning and teaching, and on the schooling and community experiences of immigrant and refugee youth through lenses of advocacy and activism.

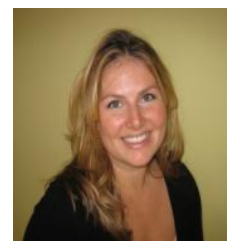

Letitia Basford is an Assistant Professor in the School of Education at Hamline University. Her research interests focus on the academic and social experiences of immigrant and refugee students in K-12 schools, and how differing school contexts affect the overall school experience and identity construction of immigrant youth.

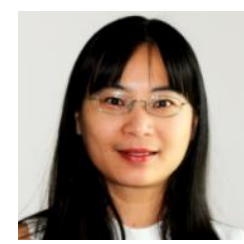

Esther Smidt is an Assistant Professor of TESL in the Department of Modern Languages at Minnesota State University, Mankato. Her research interests include immigrant identities and immigrant education, second language teacher education, computer-assisted language learning, and qualitative research methodology. 
Bigelow et al.: [Special Issue on Hmong Newcomers to Saint Paul Public Schools] S

Special Issue on Hmong Newcomers

Bigelow, Basford and Smidt: Supporting Hmong Newcomers' Academic and Social Transition

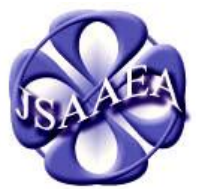

Volume 3 (2008)

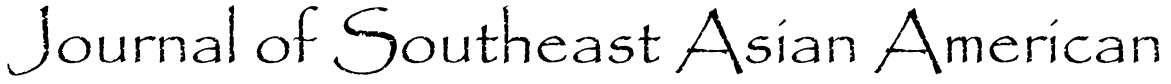

Education \& Advancement
A peer-reviewed scholarly journal published by the National Association for the Education \& Advancement of Cambodian, Laotian, and Vietnamese Americans (NAFEA)

\author{
Editor \\ Dr. Wayne E. Wright \\ University of Texas, San Antonio \\ Associate Editors \\ Dr. Chhany Sak-Humphry \\ University of Hawaii \\ Dr. KimOanh Nguyen-Lam \\ California State University, Long Beach \\ Book Review Editor \\ Vichet Chhuon \\ University of California-Santa Barbara \\ Creative Works Editor \\ Phouang Hamilton \\ Washington Office of Superintendent of Public Instruction \\ Special Advisor \\ Anne Frank \\ University of California, Irvine, Southeast Asian Archives
}

Editorial Assistant

Mariana Kuhl

University of Texas, San Antonio

Comments and questions for the editorial staff may be directed to jsaaea@ lists.sis.utsa.edu

\title{
Editorial Review Board
}

\author{
Dr. Carl L. Bankston III \\ Tulane University \\ Dr. Phala Chea \\ Lowell Public Schools \\ Dr. Changming Duan \\ University of Missouri, Kansas City \\ Dr. Nancy H. Hornberger \\ University of Pennsylvania \\ Dr. Peter Nien-Chu Kiang \\ University of Massachusetts, Boston
}

\author{
Dr. Pollie Bith-Melander \\ Asian and Pacific Islander Wellness Center \\ Dr. George Chigas \\ University of Massachusetts, Lowell \\ Dr. Sophal Ear \\ U.S. Naval Postgraduate School \\ Dr. Samlong Inthaly \\ Minneapolis Public Schools \\ Dr. Kevin K. Kumashiro \\ University of Illinois, Chicago
}


Bigelow, Basford and Smidt: Supporting Hmong Newcomers' Academic and Social Transition

Dr. Stacey Lee

University of Wisconsin, Madison

Dr. Sue Needham

California State University, Dominguez Hills

Dr. Max Niedzwiecki

Daylight Consulting Group

Dr. Clara Park

California State University, Northridge

Dr. Loan T. Phan

University of New Hampshire

Dr. Karen Quintiliani

California State University, Long Beach

Dr. Fay Shin

California State University, Long Beach

Dr. Yer J. Thao

Portland State University

Dr. Khatharya Um

University of California, Berkeley

Dr. Terrence G. Wiley

Arizona State University
Dr. David Chanpannha Ley

Montgomery County Public Schools

Dr. Bic Ngo

University of Wisconsin-Madison

Dr. Leakhena Nou

California State University, Long Beach

Dr. Mark Pfeifer

Texas A\&M University, Corpus Christi

Dr. Bounlieng Phommasouvanh

Minnesota Department of Education

Dr. Kalyani Rai

University of Wisconsin, Milwaukee

Dr. Nancy J. Smith-Hefner

Boston University

Dr. Myluong Tran

San Diego State University

Dr. Linda Trinh Vo

University of California, Irvine

Dr. Zha Blong Xiong

University of Minnesota

Dr. Kou Yang

California State University, Stanislaus

\section{Doctoral Student Editorial Review Board}

\section{Keo Chea}

University of Pennsylvania

Loan Dao

University of California, Berkeley

Ha Lam

Arizona State University

Vanna Som

Harvard University

Giang Pham

University of Minnesota

Tinou Tran

University of Houston, Texas

Phitsamay Sychitkokhong Uy

Harvard University
Vichet Chhuon

University of California, Santa Barbara

Annie BichLoan Duong

San Joaquin County Office of Education

Ravy Lao

University of California, Santa Barbara

Rassamichanh Souryasack

University of California, Santa Barbara

Layheng Ting

State University of New York, Albany

Loan Tran

University of California, Santa Barbara

Yang Sao Xiong

University of California, Los Angeles 